\section{Fatal thrombosis after administration of activated prothrombin complex concentrates in a patient supported by extracorporeal membrane oxygenation who had received activated recombinant factor VII}

\author{
Jack D. Bui, MD, PhD, ${ }^{a}$ George D. Despotis, MD, ${ }^{\mathrm{a}, \mathrm{b}}$ Elbert P. Trulock, MD, ${ }^{\mathrm{c}}$ \\ G. Alexander Patterson, MD, ${ }^{d}$ and Lawrence T. Goodnough, MD, ${ }^{\mathrm{a}, \mathrm{c}}$ St Louis, Mo
}

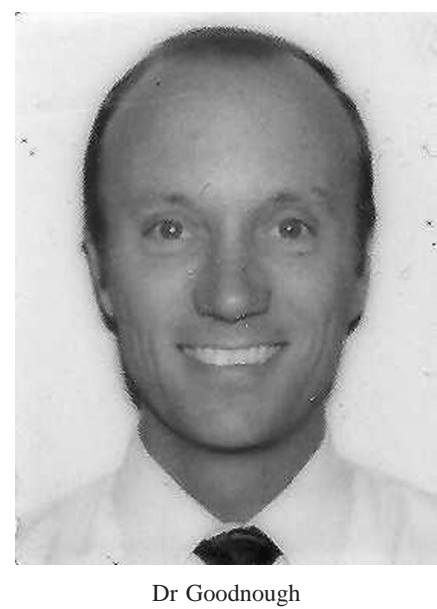

$\mathrm{E}$ xcessive bleeding after cardiac surgery has been attributed to perturbations of the hemostatic system as a result of surgical trauma and the use of cardiopulmonary bypass (CPB). Factor concentrates, such as recombinant activated factor VII (rFVIIa) and activated prothrombin complex concentrates (APCCs, Factor Eight Inhibitor Bypass Inhibitor [FEIBA]; Baxter Healthcare Corporation, Deerfield, Ill) have been used with variable success and complications. We describe a case in which a patient supported by extracorporeal membrane oxygenation (ECMO) received two doses of rFVIIa without apparent complication. He then received APCC and subsequently died of massive thrombosis. We discuss the use of factor concentrates in the surgical setting and make recommendations.

\section{Clinical Summary}

A 56-year-old man underwent retransplantation on November 19, 2000, for bronchiolitis obliterans syndrome that developed after bilateral lung transplantation in 1993 for chronic obstructive pulmonary disease. The patient had normal hepatic and renal function and a normal coagulation profile before surgery. After an uneventful anesthetic induction, CPB was required to maintain acceptable oxygenation during the intraoperative period. There was profuse blood loss during the procedure, which necessitated transfusion of large amounts of blood products (Figure 1). Continued blood loss was observed at the end of the operation, despite discontinuation and reversal of heparin. Attempts to terminate CPB were unsuc-

From the Departments of Pathology and Immunology, ${ }^{a}$ Anesthesiology, Internal Medicine, ${ }^{\mathrm{c}}$ and Surgery, ${ }^{\mathrm{d}}$ Washington University School of Medicine, St Louis, Mo

Received for publication April 11, 2002; accepted for publication April 24, 2002

Address for reprints: Lawrence T. Goodnough, MD, Department of Pathology and Immunology, Box 8118, Washington University School of Medicine, 660 S Euclid, St Louis, MO 63110 (E-mail: goodnough@ labmed.wustl.edu).

J Thorac Cardiovasc Surg 2002;124:852-4

Copyright $(9) 2002$ by The American Association for Thoracic Surgery

$0022-5223 / 2002 \$ 35.00+0 \quad \mathbf{1 2 / 5 4 / 1 2 6 0 3 8}$

doi: $10.1067 / \mathrm{mtc} .2002 .126038$ cessful, and ECMO was instituted without heparin. The patient was transported to the intensive care unit with ECMO support. In the intensive care unit, drainage from the chest tubes exceeded 1 $\mathrm{L} / \mathrm{h}$ for 2 hours, with no response to continued transfusion of blood components. Therefore, $7.8 \mathrm{mg}(90 \mu \mathrm{g} / \mathrm{kg}$ ) of rFVIIa (NovoSeven; NovoNordisk, Copenhagen, Denmark) was administered, with subsequent decrease in chest tube output (Figure 1). Continued bleeding necessitated returning the patient to the operating room for exploration. In the operating room, the cannulation site was rechecked and judged to be secure, and no discrete bleeding site was identified. A 4.8-mg dose of rFVIIa was given (exact time was not noted in the records). After the operation, the bleeding persisted and the patient required additional blood products. Chest tube drainage had decreased to approximately $300 \mathrm{~mL} / \mathrm{h}$ of sanguineous fluid since the administration of the second dose of rFVIIa. About 6 hours after the last dose of rFVIIa, chest tube drainage had reached a plateau of $300 \mathrm{~mL} / \mathrm{h}$, the patient required more blood products, and it was decided that additional hemostasis was required. At this time, because rFVIIa was not available, APCC was given (the amount was not recorded). At 1:58 am, several minutes into the infusion of APCC, the patient became hypotensive and bradycardic, and flow through the ECMO circuit decreased to $0.5 \mathrm{~L} / \mathrm{min}$. Despite bedside thoracotomy and open cardiac massage, the patient died within 20 minutes. During resuscitation, minimal myocardial contraction was apparent, the heart felt full and immobile, and clots were noted in the ECMO tubing. The patient's family declined autopsy.

\section{Discussion}

Because there was no autopsy, a definitive cause of death cannot be determined. However, the final event appeared to be massive intracardiac and ECMO circuit thrombosis. The thrombotic complications of APCC have limited the use of APCC for the treatment of bleeding. ${ }^{1}$ Notably, the package insert for FEIBA states that its use is contraindicated in the presence of disseminated intravascular coagulation. In this case, the administration of APCC seemed to precipitate massive thrombosis. This occurred at least 6 hours after the last dose of rFVIIa had been administered. Because the half-life of rFVIIa is 2.3 to 3.0 hours in the bleeding state (as reviewed by Ingerslev and coworkers ${ }^{2}$ ), we conclude that APCC, rather than rFVIIa, was the main contributing factor to the death of this patient. 


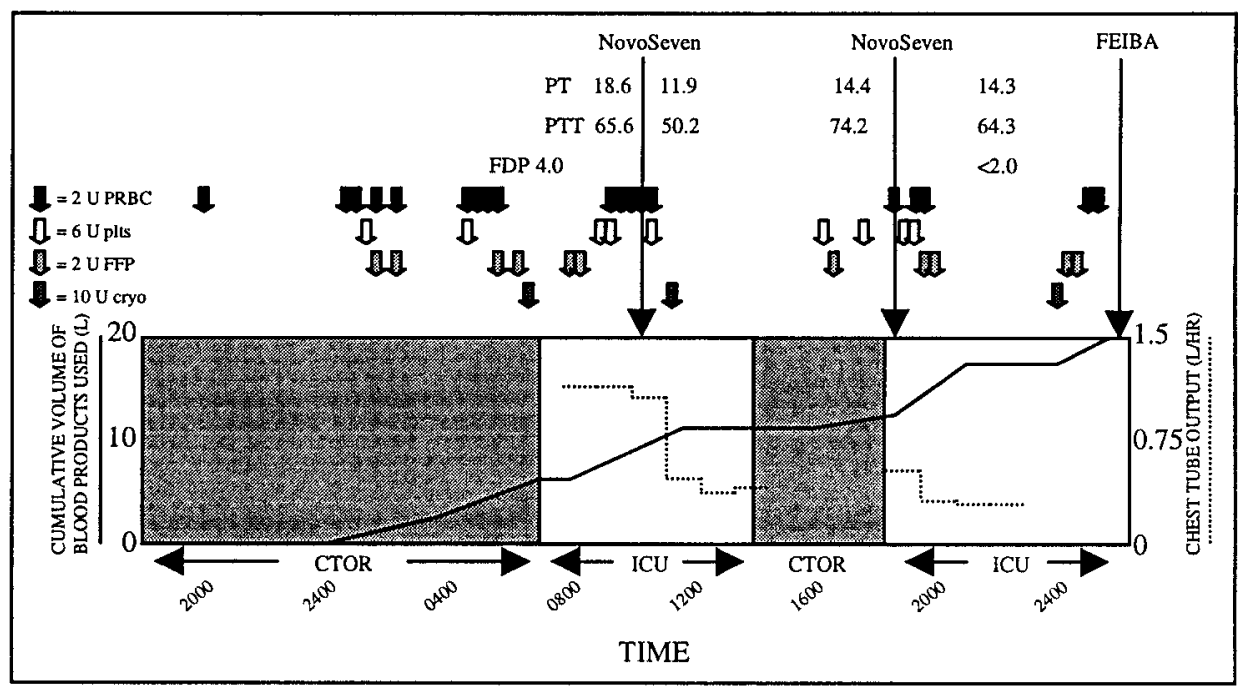

Figure 1. Blood product use, chest tube output, and coagulation test values plotted against time. Shaded areas represent time spent in operating room. Patient died at 2 am after FEIBA administration. PT, Prothrombin time; PTT, partial thromboplastin time; PRBC, packed red blood cells; plts, platelets; FFP, fresh-frozen plasma; cryo, cryoprecipitate; CTOR, cardiothoracic operating room; ICU, intensive care unit.

In contrast to the thrombotic effect of $\mathrm{APCC}$, the effect of rFVIIa on our patient was a reduced chest tube output without apparent thrombotic event. Various reports have documented the success of using rFVIIa for a variety of nonapproved situations, including traumatic bleeding, postoperative lower gastrointestinal bleeding, warfarin reversal, liver disease, and platelet dysfunction (as reviewed by Hedner and Erhardtsen ${ }^{3}$ ). Thrombotic complications of rFVIIa have been described in patients with preexisting risk factors, such as cardiac disease, advanced age, and anomalous vasculature. We document in this case a beneficial effect of rFVIIa despite the presence of thrombotic risk factors (postoperative setting of ECMO without heparin). The greater thrombotic potential of APCC versus rFVIIa is supported mechanistically by an in vitro assay, which showed that APCC could generate more free thrombin than could rFVIIa. ${ }^{4}$ It should be emphasized that the mechanism of action of rFVIIa in vivo is thought to be regulated, localized thrombin generation on activated platelet membranes. ${ }^{3}$ The ability of APCC to generate thrombin in vitro in the absence of platelet membranes suggests that its prothrombotic tendencies may be due to dysregulated thrombin production in vivo.

Excessive bleeding after cardiac surgery has been attributed to a disseminated intravascular coagulation-like phenomenon that involves uncontrolled activation of both the hemostatic and fibrinolytic systems. ${ }^{5}$ The hemostatic system is activated by interactions of blood components with CPB surfaces as well as by initiation of the extrinsic clotting pathway by surgical trauma. The fibrinolytic system is activated by release of tissue plasminogen activator, which can be promoted by $\mathrm{CPB}$-mediated contact activation of factor XII and thrombin, hypothermia, and traumatized endothelial cells. Moreover, returned blood from the pericardial suction has been shown to contain both tissue factor and tissue plasminogen activator, potentially leading to activation of both hemostasis and fibrinolysis. Numerous strategies have been pro- posed to attenuate the hemostatic disturbances associated with CPB. Notably, in a recent prospective randomized trial of patients undergoing procedures that necessitated $\mathrm{CPB}$, those who received $35 \%$ more heparin had lessened use of non-red cell blood products and better preservation of consumable coagulation factors (as reviewed by Despotis and associates ${ }^{5}$ ). It is thought that the use of heparin in this setting stabilized the hemostatic system, thereby leading to decreased bleeding.

In conclusion, administration of two doses of rFVIIa resulted in reduced chest tube output without evidence of thrombosis. Subsequent administration of APCC resulted in fatal thrombosis. On the basis of our observations and a review of the literature, we conclude that the thrombotic potential of rFVIIa is much lower than that of APCC, and therefore its use should be preferred to that of APCC, particularly for patients who have prothrombotic risk factors. In addition, we suggest initiation of anticoagulation before administration of factor concentrates in patients who have an ongoing stimulus for hemostatic system activation and thrombosis (eg, ECMO). This last recommendation is made with the intent of preventing catastrophic thrombosis at the expense of continued bleeding. On the basis of our experience with this patient and others at this institution, we recommend that factor concentrates be given only if the following criteria are met: (1) life-threatening bleeding is greater than 500 to $1000 \mathrm{~mL} / \mathrm{h}$, (2) there is an unidentified source of bleeding other than a surgical source, and (3) bleeding is unresponsive to pharmacologic agents (eg, L-deamino8-D-arginine vasopressin, aprotinin, or aminocaproic acid) and aggressive transfusion support with several rounds of hemostatic components (2-3 units of single-donor platelets, 4-6 units of freshfrozen plasma, and 10-20 units of cryoprecipitate). These criteria have been instituted at our facility and are generally met before the release of factor concentrates. 


\section{References}

1. Lusher JM. Use of prothrombin complex concentrates in management of bleeding in hemophiliacs with inhibitors-benefits and limitations. Semin Hematol. 1994;31(2 Suppl 4):49-52.

2. Ingerslev J, Christiansen K, Calatzis A, Holm M, Sabroe Ebbesen L. Management and monitoring of recombinant activated factor VII Blood Coagul Fibrinolysis. 2000;11 Suppl 1:S25-30.
3. Hedner U, Erhardtsen E. Potential role for rFVIIa in transfusion medicine. Transfusion. 2002;42:114-24.

4. Gallistl S, Cvirn G, Muntean W. Recombinant factor VIIa does not induce hypercoagulability in vitro. Thromb Haemost. 1999;81: 245-9.

5. Despotis GJ, Avidan MS, Hogue CW. Mechanisms and attenuation of hemostatic activation during extracorporeal circulation. Ann Thorac Surg. 2001;72:S1821-31.

\section{Online-www.aats.org}

Now you can get The Journal of Thoracic and Cardiovascular Surgery online. The Journal online brings you faster delivery time, easy searching of current and back issues, links to PubMed, AATS, WTSA, and other important sites, and more. Visit the Journal online today.

\section{Receive tables of contents by e-mail}

To receive the tables of contents by e-mail, sign up through our Web site at http://www.mosby.com/jtcvs

Choose E-mail Notification

Simply type your e-mail address in the box and click the Subscribe button. Alternatively, you may send an e-mail message to majordomo@mosby.com. Leave the subject line blank and type the following as the body of your message: subscribe jtcvs_toc

You will receive an e-mail to confirm that you have been added to the mailing list.

Note that TOC e-mails will be sent out when a new issue is posted to the Web site. 